\title{
Comparative Analysis based on Simulation \& Design Aspects of Three Phase Four Switch Inverter for Industrial Applications
}

\author{
Sudeshna Ghosh \\ Electrical Engineering Department, \\ Maulana Azad National Institute of Technology, Bhopal, Madhya Pradesh, India \\ Corresponding author: sudeshna2012@gmail.com \\ Pankaj Swarnkar \\ Electrical Engineering Department, \\ Maulana Azad National Institute of Technology, Bhopal, Madhya Pradesh, India \\ E-mail: p_swarnkar@yahoo.co.in \\ D. M. Deshpande \\ Electrical Engineering Department, \\ Maulana Azad National Institute of Technology, Bhopal, Madhya Pradesh, India \\ E-mail: dinesh.deshpande1949@gmail.com
}

(Received May 29, 2019; Accepted September 8, 2019)

\begin{abstract}
The industrial and utility sector perceives a shift in the paradigm of technology moving with at a very fast pace with the advent of applications like AC drives, FACTS devices, uninterruptible power supplies and many more. These applications are based on power electronics utilizing voltage source inverters (VSIs) dependent technology. The VSI based applications embodies some of the most pertinent and corroborated up gradation to cater the new challenges existing today. The essence of this paper is to draw attention towards benefits and limitations of using four switch three phase voltage source inverter (FSTPVSI) and present a comparative analysis based on technical, economical and performance parameters with six switch three phase voltage source inverter (SSTPVSI) for industrial applications. Finally, after visualizing the wide scope of research in the field of FSTPVSI, an effort has been made to simulate the both FSTPVSI \& SSTPVSI using SIMULINK environment. Numerous design aspects based on technical and economic aspects demonstrate that by slightly modifying the pulse width modulation technique comparable results can be achieved from FSTPVSI topology.
\end{abstract}

Keywords- Voltage source inverter (VSI), Space vector modulation (SVM), Four switch three phase inverter (FSTPI), Six switch three phase inverter (SSTPI), Pulse-width modulation (PWM).

\section{Introduction}

Inverters in the framework of power-electronics circuits had an unprecedented development at a remarkable pace over the past few decades. This unparalleled growth is the result of emerging application areas like photovoltaic, wind power generation, HVDC transmission and highly efficient electrical power drives. This growth is very well supported by the improvement in the field of device technology (Salcone et al., 2009; Kabalyk, 2016) and availability of power switches like MOSFET, IGBT, and GTO etc. which possess the potential of delivering power in a wide range (Krause et al., 2002; Bose, 2004; Wu, 2006). The solid-state inverters can be categorized according to circuit arrangement into two categories based on the type of input source on the DC side (either voltage or current) as a voltage or a current source inverter. Generally, Voltage Source Inverters (VSIs) have a capacitor of high capacity connected across the DC source to keep the input voltage constant. They provide voltage with required control over the 
International Journal of Mathematical, Engineering and Management Sciences

Vol. 4, No. 6, 1325-1340, 2019

https://dx.doi.org/10.33889/IJMEMS.2019.4.6-104

magnitude, frequency and phase and type of application decides the nature of voltage and frequency whether constant or variable. Voltage source inverters have proved to be a boon in the field of medium and large power segment industrial applications by increasing the reliability and faster dynamic response in spite of the presence of other circuit topologies. This notable rise was supported by the initiation of fast switching devices with elevated ratings as well as expansion of sophisticated control techniques (Murai et al., 1992; Bowes and Lai., 1997). The benchmark in inverter circuit topology evolved over the last few decades is the three-phase bridge inverter for variable frequency drive (VFD) purpose. They comprise of three legs and all total six switches, which is an expansion of the single-phase H-bridge inverter with an extra leg (Lee and Kim, 2007). Although Six Switch Three Phase Inverter (SSTPI) marks its presence in terms of greater reliability and dynamic response. At the same time suffers from serious drawbacks like added cost, elevated switching losses and intricate algorithm predominantly in the lower power ranges (Hava et al., 1999; Kwasinski et al., 2003; Hava and Emre, 2009). In recent years, researchers are persistently trying to develop new strategies for power converters with reduced losses, increased efficiency and reduced cost. Four switch three phase inverters (FSTPI) with only two legs have shown promising alternative in comparison to the six switch three leg inverters due to the benefits like reduced component count, reduced price due to reduced requirement of the additional circuitry \& conduction switching losses (Lee and Lee., 1998).

To exploit the benefits from various VSI configurations tremendous research in the improvement of PWM strategies were developed since 1970. Space Vector PWM (SVPWM or simply SVM) has emerged as the most suited PWM technique in the mid-1980's for SSTPI topologies (Narayanan and Ranganathan., 2002), claims an edge over regular sampled PWM in terms of performance and simplicity in implementation. In pulse width modulation the DC voltage is switched on and off very rapidly using the inverter switches. To produce a sine wave a large number of DC pulses are generated such that the first has a very short time followed by increasing the on periods until the widest pulse appears at the center of the positive half of the sine wave. Similar pattern is followed in the inverted fashion for the negative half of the wave (Correa et al., 2006). Then smaller until the DC is inverted and the same pattern repeats for generating the negative part of the sine wave. By the end of 1990s researchers envisioned the SVM for FSTPI topologies which gain tremendous popularity over SSTPI due to formerly mentioned advantages (Klima, 2006).

In spite of the aforesaid advantages, the FSTPI strategy is penalized due to: (i) inflated voltage stresses on power devices and machine on maintaining same output voltage (ii) reduction in voltage gain thereby increasing the rating of the devices (iii) voltage variation across the DC link capacitors thereby loading the capacitors. These drawbacks are contributed due to the application of unbalanced voltage vectors produced in the $\alpha-\beta$ plane by the DC link capacitors. In the process of refinement in the FSTPI PWM strategies, considerable efforts have been made to overcome the impact of unbalanced DC link voltage by calculating the switching times for four switch inverter using double Fourier integral analysis (Wang et al., 2011), whereas researchers have proposed fuzzy logic based (Thamizhazhagan and Sutha, 2017; Yousef and Abo-Elyousr, 2017) and predictive (Zhou et al., 2015), MRAS based (Vallabhai et al., 2012) methods of vector selection table which imitates the six switch inverter eliminating complexity in implementation scheme (Badsi et al., 2013). Various control schemes used in modern industrial drives is been analysed by (Ghosh et al., 2019) thereby highlighting the advantages and limitations of each scheme. In this paper the mathematical framework is presented for SSTPI and FSTPI configurations. Based on the mathematical modeling simulations are carried out to validate the results. 
International Journal of Mathematical, Engineering and Management Sciences

Vol. 4, No. 6, 1325-1340, 2019

https://dx.doi.org/10.33889/IJMEMS.2019.4.6-104

\section{Review of Pulse Width Modulation and Control Scheme for SSTPI}

The output AC voltage of a VSI comprises of voltage pulses of magnitude $\pm V_{\mathrm{dc}} / 2$ for a DC link capacitor voltage of $\mathrm{V}_{\mathrm{dc}}$. These modulated voltage outputs possess non- sinusoidal behavior. To facilitate sinusoidal behavior suitable modulation schemes are used to design the width of pulses, which not only controls the switching time but facilitates the required switching sequence. The outcome of PWM techniques are generation of voltage of precise magnitude with phase and pushing the harmonic content to the higher frequency range thus easing the filtering requirements. In the mid 80's several modulation techniques emerged out of which SVM remarkably gained popularity as a powerful, feasible and widespread approach in power conversion for various industrial applications. Figure 1 shows the whole ideology of SSTPI whose output in the form of pulses can be fed to any three phase load like AC motor. This technique utilizes the power devices of the three phase inverter in such a well apprenticed manner to obtain the appropriate inverter states. The space vector concept precisely estimates the most suitable instant of pulse placement in one switching cycle. This helps in achieving superior harmonic performance. The whole ideology of the space vector principle is pivoted around the eight possible switching states that include six active and two zero/null states $\left(\mathrm{V}_{0}, \mathrm{~V}_{7}\right)$ of the VSI (Zhou and Wang, 2002). The non-zero states $\left(\mathrm{V}_{1}-\mathrm{V}_{6}\right)$ occupy the positions in the $\alpha-\beta$ plane as stationary vectors in six sectors of $60^{\circ}$ duration each depicted in Figure 2, the null state results in short circuit on the output voltage. The turning on and off of the upper and lower switches determine the switching states of the inverter.

Here the DC voltage to be fed to the inverter is generated by the front-end rectifier through DC link capacitor. The DC is then inverted to AC and converted from 3 to 2 phase $\alpha-\beta$ components which can be represented in space vector notation signifying the generation of a voltage vector rotating with an angular velocity $\omega \mathrm{t}=\theta$ using the following equations:

Three phase voltages are given by:

$V_{a n}(t)+V_{b n}(t)+V_{c n}(t)=0$

Above three phase voltages can be converter to two phase voltages by the relation:

$\left[\begin{array}{l}V_{\alpha}(t) \\ V_{\boldsymbol{\beta}}(t)\end{array}\right]=\frac{2}{3}\left[\begin{array}{ccc}\cos 0 & \cos \frac{2 \pi}{3} & \cos \frac{4 \pi}{3} \\ \sin 0 & \sin \frac{2 \pi}{3} & \sin \frac{4 \pi}{3}\end{array}\right]\left[\begin{array}{c}V_{a n}(t) \\ V_{b n}(t) \\ V_{c n}(t)\end{array}\right]$

The space vector representation can be given by:

$\vec{V}(t)=v_{\alpha}(t)+j v_{\beta}(t)$

On substituting (2) in (3),

$\vec{V}(t)=\frac{2}{3}\left[v_{a n}(t) e^{j 0}+v_{b n}(t) e^{j \frac{2 \pi}{3}}+v_{c n}(t) e^{j \frac{4 \pi}{3}}\right]$ 
International Journal of Mathematical, Engineering and Management Sciences

Vol. 4, No. 6, 1325-1340, 2019

https://dx.doi.org/10.33889/IJMEMS.2019.4.6-104

The space vector can be represented in a general form as:

$\vec{V}_{k}=\frac{2}{3} V_{d c} e^{j(k-1) \frac{\pi}{3}}$, where $\mathrm{k}=1,2 \ldots . ., 6$.

The reference voltage vector in any of the sector is given by:

$$
\begin{aligned}
& \vec{V}_{r e f}=V_{r e f} e^{j \theta} \\
& \vec{V}_{r e f} T_{s}=\vec{V}_{1} T_{1}+\vec{V}_{2} T_{2}+\vec{V}_{o} T_{0} \\
& T_{s}=T_{1}+T_{2}+T_{0}
\end{aligned}
$$

where $T_{s}$ is the switching period. From equation (6), (7) and (8) the time elapsed by vectors $V_{1}$ and $\mathrm{V}_{2}$ in Sector I may be calculated as follows, which may then be implemented for other sectors also:

$$
\begin{aligned}
& V_{1}=\frac{2}{3} V_{D C}, \quad V_{2}=\frac{2}{3} V_{D C} \times e^{j \frac{\pi}{3}} \text { and } V_{O}=0 \\
& V_{r e f} e^{j \theta} \times T_{s}=\frac{2}{3} V_{D C} \times T_{1}+\frac{2}{3} V_{D C} e^{j \frac{\pi}{3}} \times T_{2} \\
& V_{r e f} T_{s}[\cos \boldsymbol{\theta}+j \sin \theta]=\frac{2}{3} V_{D C} \times T_{1}+\frac{2}{3} V_{D C} \times T_{2}\left[\cos \frac{\pi}{3}+j \sin \frac{\pi}{3}\right] \\
& V_{r e f} T_{s}[\cos \boldsymbol{\theta}+j \sin \boldsymbol{\theta}]=\frac{2}{3} V_{D C} \times T_{1}+\frac{2}{3} V_{D C}\left(\frac{1}{2}+j \frac{\sqrt{3}}{2}\right) \times T_{2}
\end{aligned}
$$

Now equating the real and imaginary parts-

$$
\begin{aligned}
& V_{r e f} \cos \boldsymbol{\theta} \times T_{s}=\frac{2}{3} V_{D C} \times T_{1}+\frac{1}{3} V_{D C} \times T_{2} \\
& V_{r e f} \sin \boldsymbol{\theta} \times T_{s}=\frac{1}{\sqrt{3}} V_{D C} \times T_{2}
\end{aligned}
$$

From equation (14), the value of $\mathrm{T}_{2}$ can be obtained as:

$$
T_{2}=\sqrt{3} \frac{V_{r e f}}{V_{D C}} \sin \boldsymbol{\theta} \times T_{s}
$$

Substituting equation (15) in (13) and thus obtaining the value of $\mathrm{T}_{1}$

$$
\begin{aligned}
& V_{r e f} \cos \boldsymbol{\theta} \times T_{s}=\frac{2}{3} V_{D C} \times T_{1}+\frac{1}{3} V_{D C}\left[\sqrt{3} \frac{V_{r e f}}{V_{D C}} \sin \boldsymbol{\theta} \times T_{s}\right] \\
& V_{r e f} \times T_{s}\left[\cos \boldsymbol{\theta}-\frac{1}{\sqrt{3}} \sin \boldsymbol{\theta}\right]=\frac{2}{3} V_{D C} \times T_{1}
\end{aligned}
$$


International Journal of Mathematical, Engineering and Management Sciences

Vol. 4, No. 6, 1325-1340, 2019

https://dx.doi.org/10.33889/IJMEMS.2019.4.6-104

$T_{1}=\frac{3}{2} \times \frac{V_{r e f}}{V_{D C}} \times T_{s}\left[\frac{\sqrt{3}}{2} \cos \theta-\frac{1}{2} \sin \theta\right]$

$T_{1}=\frac{3}{2} \times \frac{V_{r e f}}{V_{D C}} \times T_{s}\left[\sin \frac{\pi}{3} \cos \theta-\cos \frac{\pi}{3} \sin \theta\right]$

$T_{1}=\frac{3}{2} \times \frac{V_{r e f}}{V_{D C}} \times T_{s}\left[\sin \frac{\pi}{3}-\theta\right]$

Thus, equations (15) and (20) provides the timings in sector I, which can be extended for calculating the timing in other sectors also.

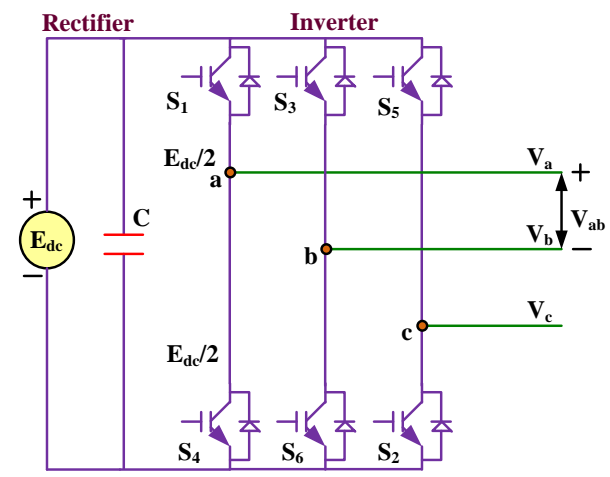

Figure 1. Schematic of SSTPI

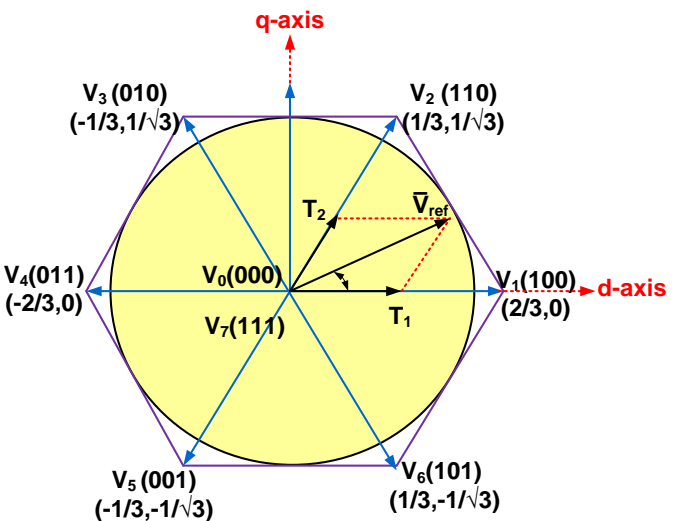

Figure 2. Space vector diagram for FSTPI

\section{Pulse Width Modulation Approach for FSTPI}

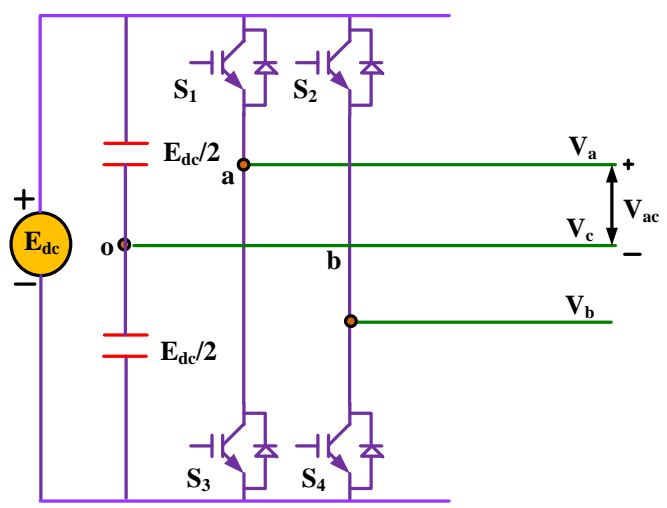

Figure 3. Schematic of FSTPI 
International Journal of Mathematical, Engineering and Management Sciences

Vol. 4, No. 6, 1325-1340, 2019

https://dx.doi.org/10.33889/IJMEMS.2019.4.6-104

The whole rectifier unit is constituted mainly by two parts; one is the front end rectifier supplied from a DC source and the other is the back end inverter with four switches (Figure 3) (Jang et al., 2008; Badsi et al., 2013). As in the case of SSTPI there were three phases which could be connected to the three phase load but for SSTPI the inverter has two output phases only whereas the third phase is attached to the mid-point of both the capacitors, thus dividing the voltage $V_{\mathrm{dc}}$ equally. The zero potential point is designated as ' $\mathrm{o}$ '. The smoothening of DC voltage is done by two DC link capacitors before feeding to the inverter. Proper gating of the four switching devices results in the generation of modulated output voltage which can be utilized for feeding any industrial applications requiring three phase voltage. FSTPI the vectors are not located at $60^{\circ}$ in $\alpha-\beta$ plane rather at $90^{\circ}$ with each other (Figure 4 ).

In the first leg switches are designated as $S_{1}$ and $S_{3}$ while the switches of the second leg are represented by $S_{2}$ and $S_{4}$. When a switch is closed it is denoted by the value '1' and when open the value is ' 0 ' (Zaky and Metwaly, 2017). As in a particular leg the two switches will not be operating simultaneously hence the operation can be expressed by the following equation:

$S_{1}+S_{2}=1$

$S_{3}+S_{4}=1$

The common mode voltages are given by:

$V_{a o}=\left(2 S_{1}-1\right) \frac{V_{d c}}{2}$

$V_{b o}=\left(2 S_{3}-1\right) \frac{V_{d c}}{2}$

$V_{c o}=0$

The phase voltages are given by:

$$
\begin{aligned}
& V_{a}=\frac{1}{3}\left(2 V_{a o}-V_{b o}\right) \\
& V_{b}=\frac{1}{3}\left(2 V_{b o}-V_{a o}\right) \\
& V_{c}=-\frac{1}{3}\left(2 V_{a o}-V_{b o}\right)
\end{aligned}
$$

two phase voltages can be derived from the three phase voltages by using:

$$
\left[\begin{array}{l}
V_{a} \\
V_{\boldsymbol{\beta}}
\end{array}\right]=\frac{2}{3}\left[\begin{array}{ccc}
1 & -\frac{1}{2} & -\frac{1}{2} \\
0 & \frac{\sqrt{3}}{2} & -\frac{\sqrt{3}}{2}
\end{array}\right]\left[\begin{array}{l}
V_{a} \\
V_{b} \\
V_{c}
\end{array}\right]
$$

For generation of the required voltage space vector $\mathrm{V}_{\text {ref, }}$, three or four voltage vectors can be used in one sampling interval $\mathrm{T}_{\mathrm{s}}$. The zero voltage vector can be synthesized by dividing $\mathrm{t}_{0}$ (duration of 
International Journal of Mathematical, Engineering and Management Sciences

Vol. 4, No. 6, 1325-1340, 2019

https://dx.doi.org/10.33889/IJMEMS.2019.4.6-104

zero vector) among two opposite vectors $\left(\mathrm{V}_{1}, \mathrm{~V}_{3}\right)$ or $\left(\mathrm{V}_{2}, \mathrm{~V}_{4}\right)$. As all the four voltage vectors are shifted by $\pi / 2$. Further-more, it can also be noted that the vectors $V_{1}$ and $V_{3}$ have amplitude equal to $V_{c} / \sqrt{ } 6$, while vectors voltage $V_{2}$ and $V_{4}$ have amplitude equal to $V_{c} / \sqrt{ } 2$.Thus the magnitude of all the four vectors is not same.

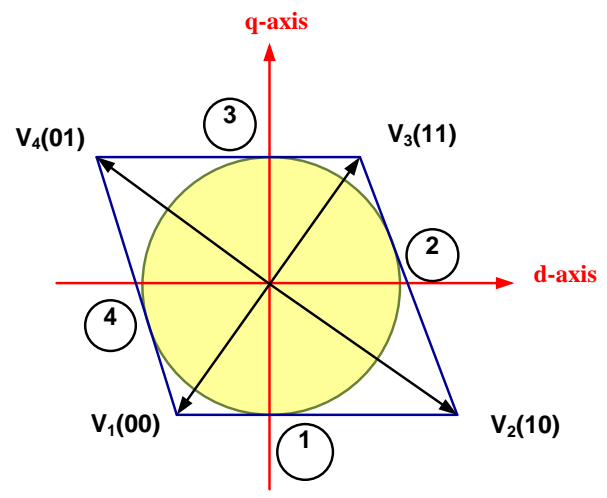

Figure 4. Space vector diagram for FSTPI

\section{Comparison of SSTPI and FSTPI Inverter Systems}

Industrial electrical drive is a very important area as it consumes considerable amount of generated electrical energy. The substantial part of the inverter system is dependent on the material cost of the components switching devices, diodes, inductors, capacitors etc. Table 1 presents the comparison between the six and four switch inverters. The first three features are the economic aspects and the rest of the features are the performance parameters on which comparison is made.

Table 1. Comparison between SSTPI \& FSTPI

\begin{tabular}{lll}
\hline Features & SSTPI & FSTPI \\
\hline No. of switches & Six & Four \\
Cost & Higher by 33\% & Less \\
Additional Circuitry & More & Less \\
Switching Losses & Higher by 33\% & Reduced by 33\% \\
Active Voltage Vectors & 6 & 4 \\
Space Vectors Diagram & Hexagon & Rhombus \\
Flux Vector Path & Circular & Polygonal \\
Impact of DC link Capacitor & Negligible & High \\
\hline
\end{tabular}

\subsection{Economic Comparison}

This section presents a cost wise comparison of six and four switch inverter components like IGBT modules, driver circuitry, transistors, capacitors and inductors. There are two major components that increases the overall cost of the inverter circuitry viz, the IGBT module and the DC link capacitors. Although the cost of DC link capacitors will be 1.75 times approximately in case of FSTPI topology but the overall cost is expected to be reduced by approximately $20 \%$ as shown in Figure 5. 
International Journal of Mathematical, Engineering and Management Sciences

Vol. 4, No. 6, 1325-1340, 2019

https://dx.doi.org/10.33889/IJMEMS.2019.4.6-104

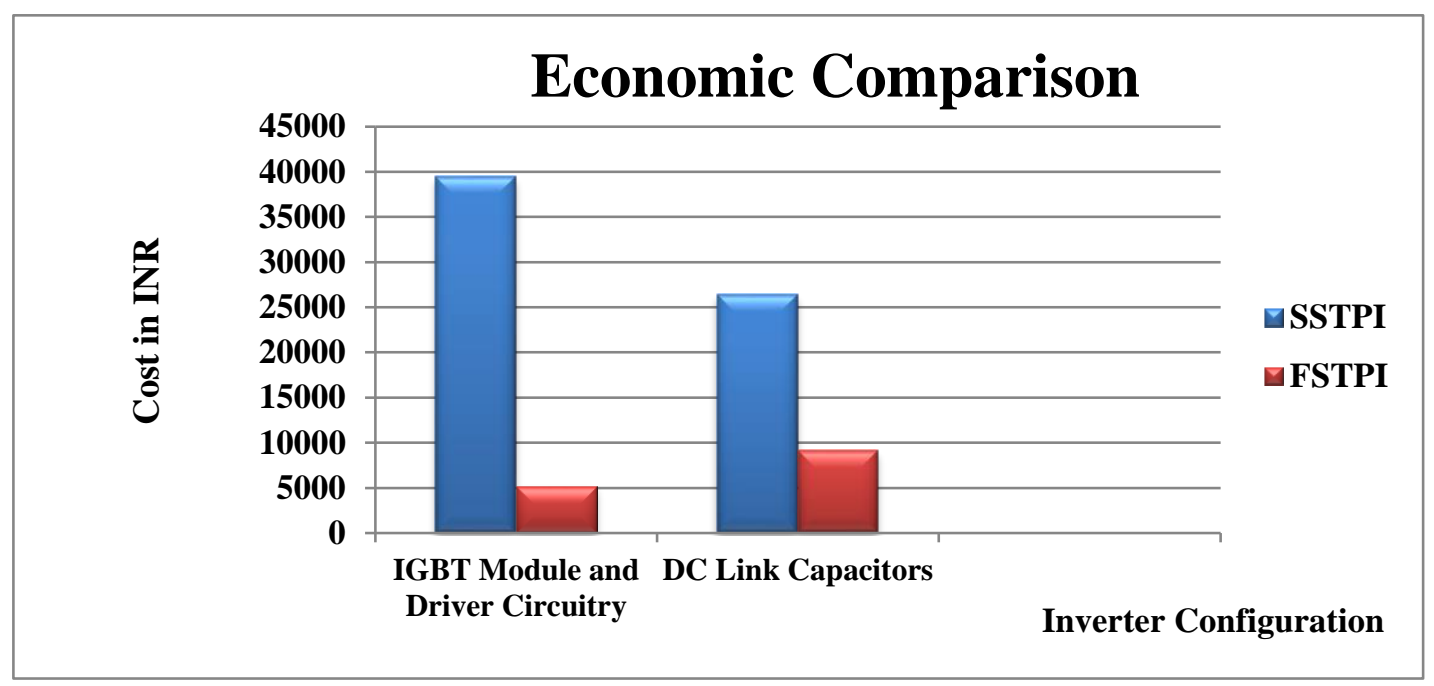

Figure 5. Economic comparison between SSTPI and FSTPI

\subsection{Loss Wise Comparison}

Although the efficiency of power electronics devices lies in the range of 97-99\% still research is going on to improve this efficiency. Efficiency needs to be addressed predominantly in case of three-phase VSIs, as these operate with relatively higher switching frequencies leading to high power losses. These power losses are mainly attributed due to the switching devices and their driver circuitry. The total power losses are the summation of the conduction and device switching losses in a semi-conductor device. The junction temperature influences the conduction losses as well.

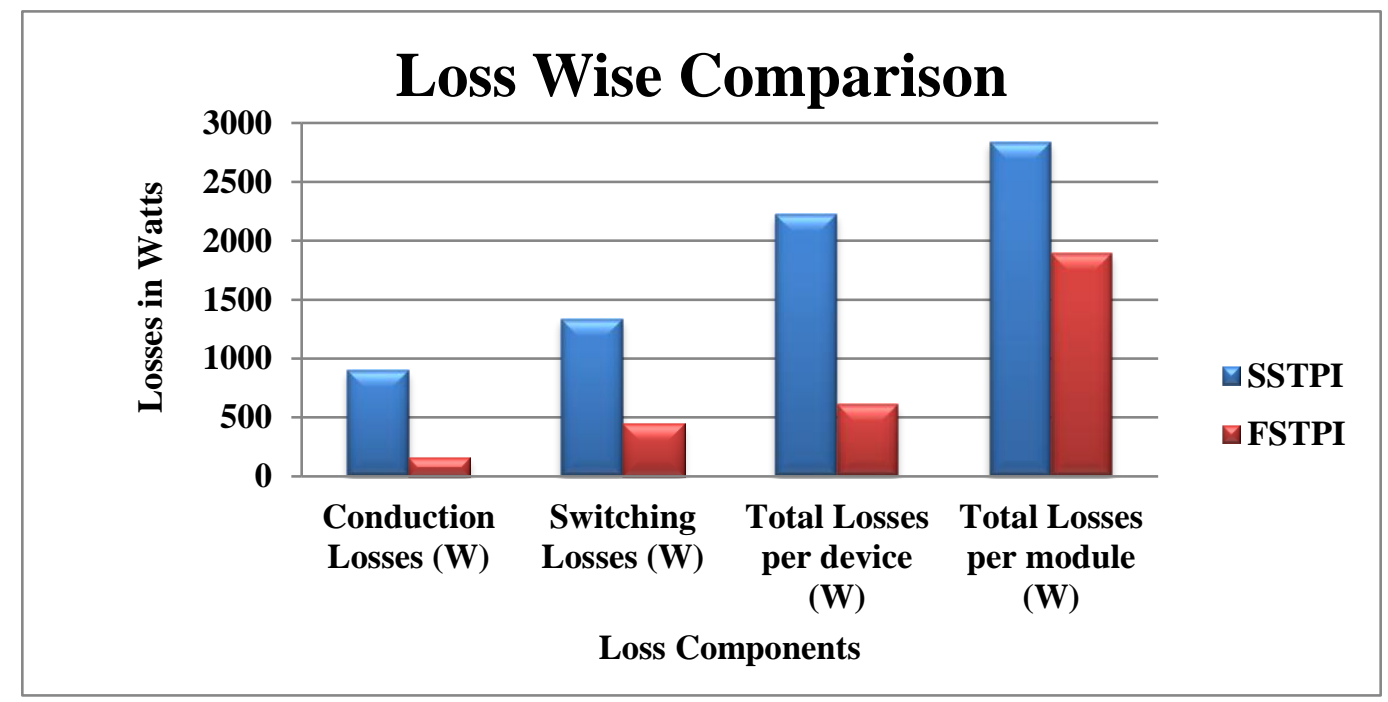

Figure 6. Loss wise comparison between SSTPI and FSTPI 
International Journal of Mathematical, Engineering and Management Sciences

Vol. 4, No. 6, 1325-1340, 2019

https://dx.doi.org/10.33889/IJMEMS.2019.4.6-104

The switching loss arises due to continuously operating the devices which are dependent on the following factors: input voltage to the three-phase VSI, load current, and the dynamic parameters of the switches (IGBT, MOSFET) etc. One of the vital aspects of reducing the losses is to improve the cooling conditions of the switches in case of pulse width modulated medium and high power inverters apart from increasing the efficiency. As switching loss is the prime cause of heat source in any power electronic device so it requires utmost importance in designing the cooling method in an inverter. Figure 6 shows loss wise comparison between the six and four switch topologies for Dynex IGBT module DIM1200ASM45-TS000 for two level VSI carried out using Infineon IPOSIM. It is seen in case of four-switch topology that the total losses as well as the switching losses are reduced by $33 \%$, which is a significant achievement.

\subsection{Impact of DC Link Capacitor}

In case of FSTPI the voltage vectors are of unequal length thus leading to unbalancing in the voltage vectors as in Figure 4. This results in the rhombus shape of the space vector diagram and polygonal shape of the flux vector trajectory. This effect is worsened in case of unbalanced voltage across the DC link capacitors leading to complete deterioration of the space vector diagram and thereby loading the capacitor. This condition would arise if any of the voltage vectors has a larger magnitude which is highlighted through space vector diagram in Figure 7 . To mitigate these effects, addition of larger dc-link capacitors provides the best possible solution but leads to large and heavy dc-link filter with a sluggish response and elevated cost (Salcone and Bond, 2009; Hee et al., 2009; Nguyen et al., 2010). Smaller value of the DC link capacitors leads to the unbalanced dc-link voltages i.e., $\mathrm{V}_{\mathrm{dcl}} \# \mathrm{~V}_{\mathrm{dc} 2}$ and the permutation of the switching states leads to the four voltage vectors with changes in both amplitude and angular position.

For mitigating the impact of DC link voltage imbalance the FSTPI can be made to replicate the operation of SSTPI by dividing the $\alpha-\beta$ plane into six sectors shown in Figure 8 and the generation of $\mathrm{V}_{\text {ref }}$ is done in the same manner as in the case for six switches. To emulate the six non-zero vectors in case of four switch inverter like that of six switch inverter, besides the two vectors $\mathrm{V}_{1}$ and $\mathrm{V}_{3}$ effective vectors $\mathrm{V}_{23 \mathrm{~A}}, \mathrm{~V}_{34 \mathrm{~A}}, \mathrm{~V}_{41 \mathrm{~A}}$ and $\mathrm{V}_{12 \mathrm{~A}}$ are proposed which are generated by using equations (30) to (33) as:

$$
\begin{aligned}
& \vec{V}_{23 A}=\frac{1}{2}\left(\vec{V}_{2}+\vec{V}_{3}\right) \\
& \vec{V}_{34 A}=\frac{1}{2}\left(\vec{V}_{3}+\vec{V}_{4}\right) \\
& \vec{V}_{41 A}=\frac{1}{2}\left(\vec{V}_{4}+\vec{V}_{1}\right) \\
& \vec{V}_{12 A}=\frac{1}{2}\left(\vec{V}_{1}+\vec{V}_{2}\right)
\end{aligned}
$$

To simulate zero vectors of six switch inverter, the operative vector $\mathrm{V}_{0 \mathrm{~A}}$ is used which can be computed by any of the following two equations:

$\vec{V}_{O A}=\frac{1}{2}\left(\vec{V}_{1}+\vec{V}_{3}\right)$ 
International Journal of Mathematical, Engineering and Management Sciences

Vol. 4, No. 6, 1325-1340, 2019

https://dx.doi.org/10.33889/IJMEMS.2019.4.6-104

$\vec{V}_{O A}=\frac{1}{2}\left(\vec{V}_{2}+\vec{V}_{4}\right)$

By synthesizing the voltage vectors in such a manner that the $\alpha-\beta$ plane is subdivided into six sectors instead of four makes the FSTPI to emulate the SSTPI operation.
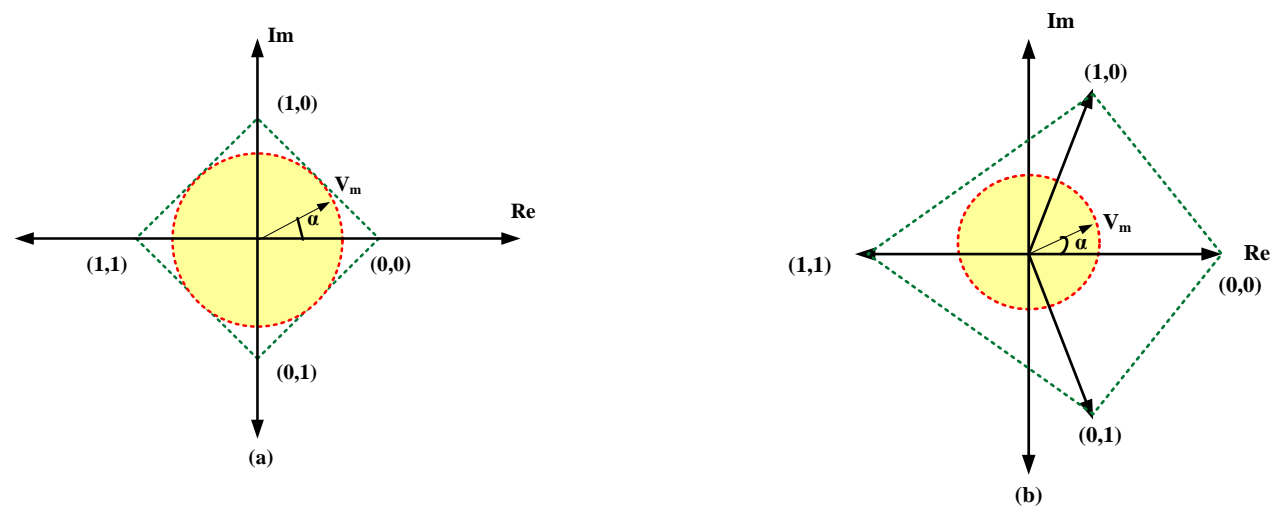

Figure 7. Space vector diagram for (a) $\mathrm{V}_{\mathrm{dc} 1}=\mathrm{V}_{\mathrm{dc} 2}$ (b) $\mathrm{V}_{\mathrm{dc} 1} \neq \mathrm{V}_{\mathrm{dc} 2}$

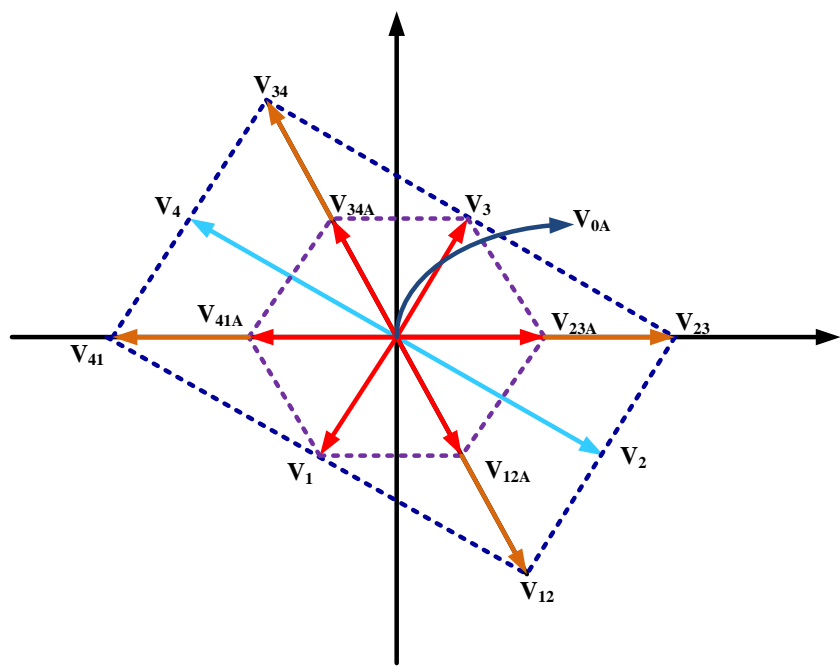

Figure 8. Synthesis of the space vector diagram for FSTPI

\section{Simulation and Results}

The performance of the system is analyzed by carrying out simulation with inverters having six and four switches. Simulation results are shown for SSTPI from Figure 9 to Figure 14 and for FSTPI configurations from Figure 15 to Figure 19 respectively. Figure 9 shows the input three phase voltages to the system, Figure 10 shows the 3 to 2-phase conversion of voltages, Figure 11 depicts sectors generated for the six switch three phase inverter followed by the output phase, line 
International Journal of Mathematical, Engineering and Management Sciences

Vol. 4, No. 6, 1325-1340, 2019

https://dx.doi.org/10.33889/IJMEMS.2019.4.6-104

and gate pulses generated by space vector modulation technique for controlling the switching instant of the inverter in Figures 12,13 and 14 respectively. In a similar manner the 3-phase input voltage, 3 to 2-phase voltage, sectors, gate pulses, three phase output voltage are shown in Figure 15 to Figure 19 for FSTPI configuration. It can be seen that the comparable performance can be obtained from FSTPI controlled through space vector modulation with reduced switch configuration thus proving to be economical. By adopting modification in the conventional space vector modulation technique for FSTPI the benefits of SSTPI can easily be harnessed.

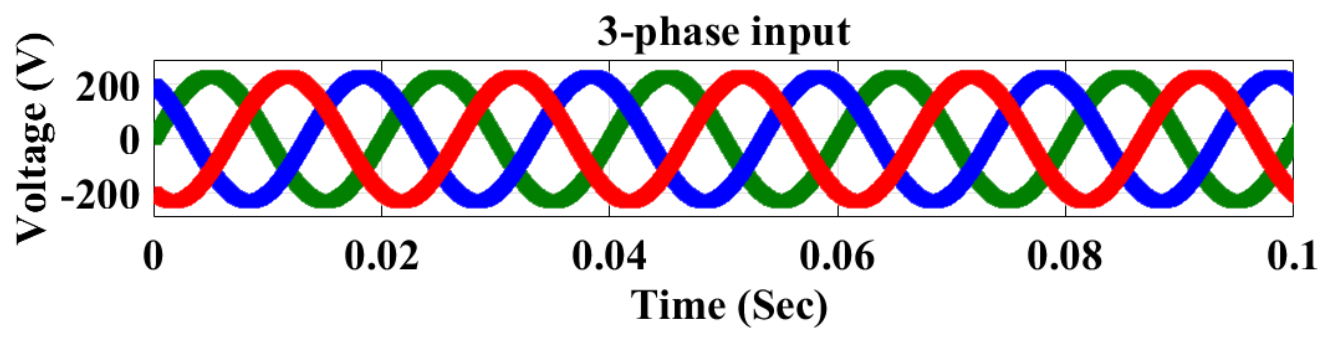

Figure 9. Three phase input voltage for SSTPI

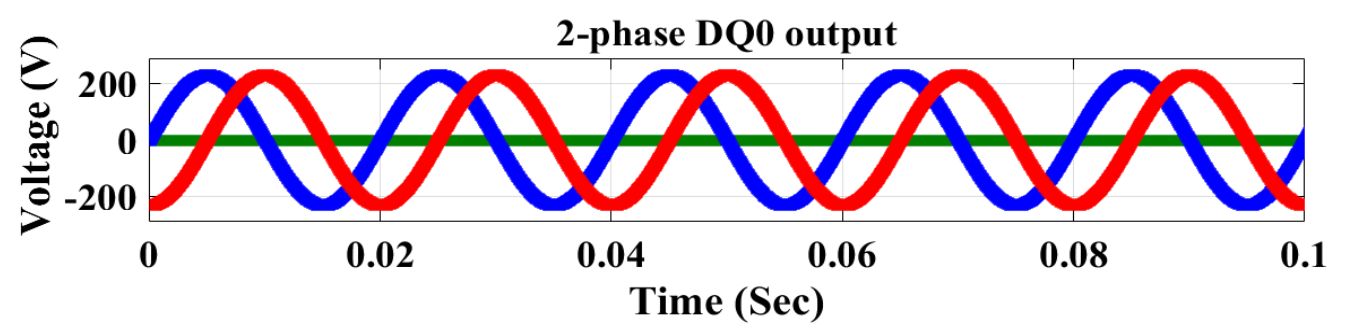

Figure 10. Two phase DQ0 output voltage of SSTPI

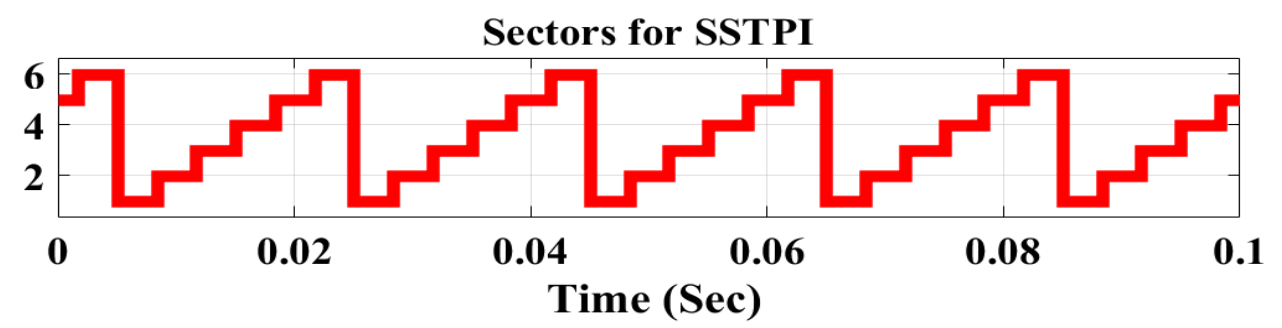

Figure 11. Sectors of pulse width modulated voltage of SSTPI 
International Journal of Mathematical, Engineering and Management Sciences

Vol. 4, No. 6, 1325-1340, 2019

https://dx.doi.org/10.33889/IJMEMS.2019.4.6-104

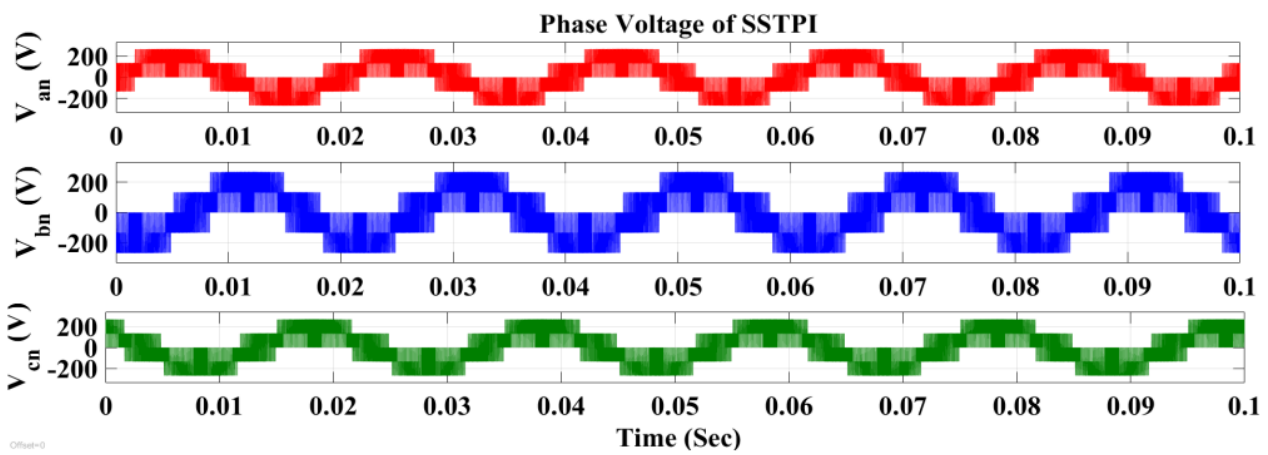

Figure 12. Output phase voltages of SSTPI

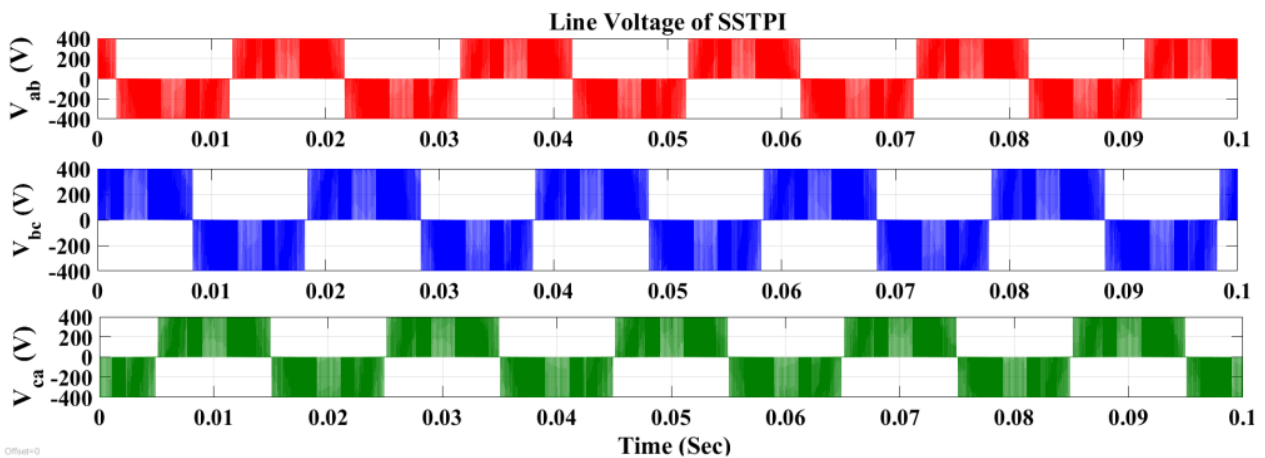

Figure 13. Output line voltages of SSTPI

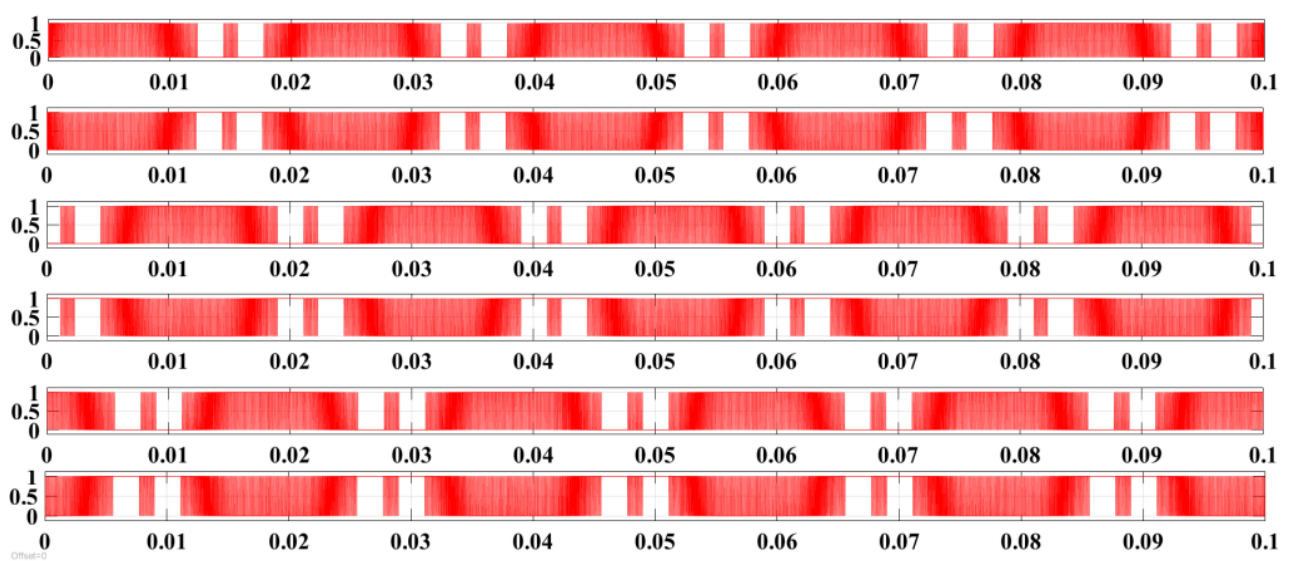

Figure 14. Gate pulses for SSTPI 
International Journal of Mathematical, Engineering and Management Sciences

Vol. 4, No. 6, 1325-1340, 2019

https://dx.doi.org/10.33889/IJMEMS.2019.4.6-104

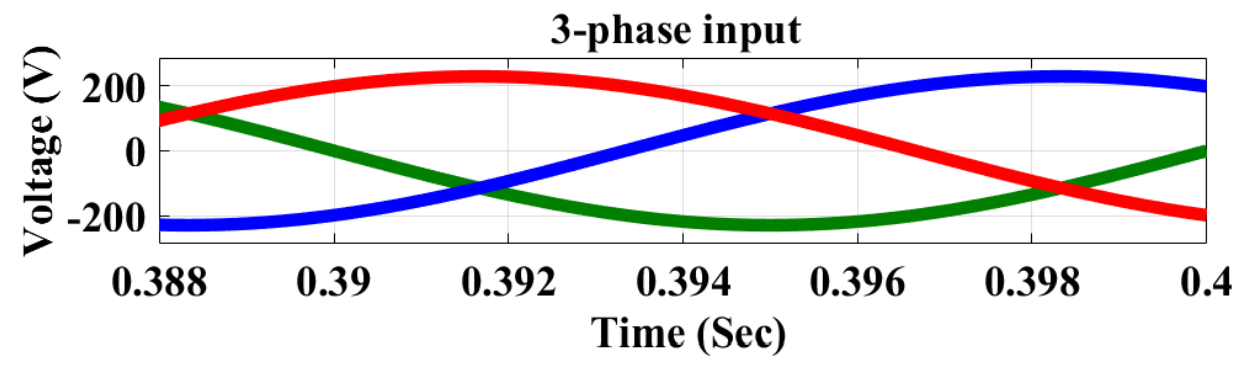

Figure 15. Three phase input voltage for FSTPI

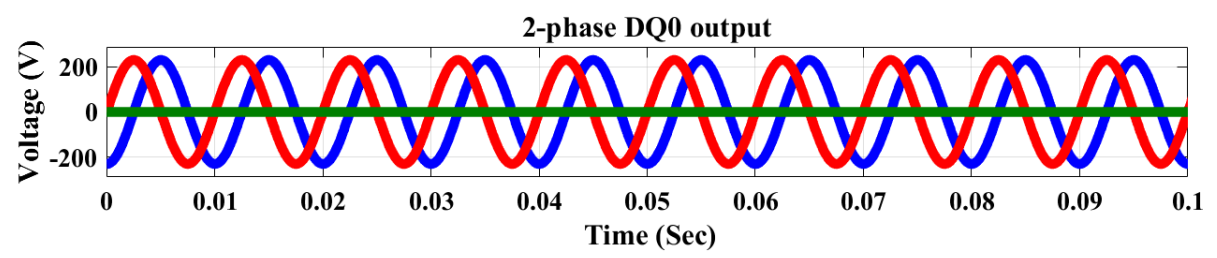

Figure 16. Two phase DQ0 output voltage of FSTPI

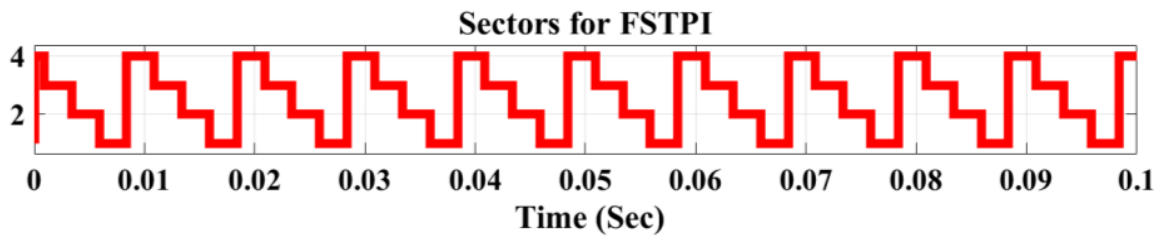

Figure 17. Sectors of pulse width modulated voltage of FSTPI

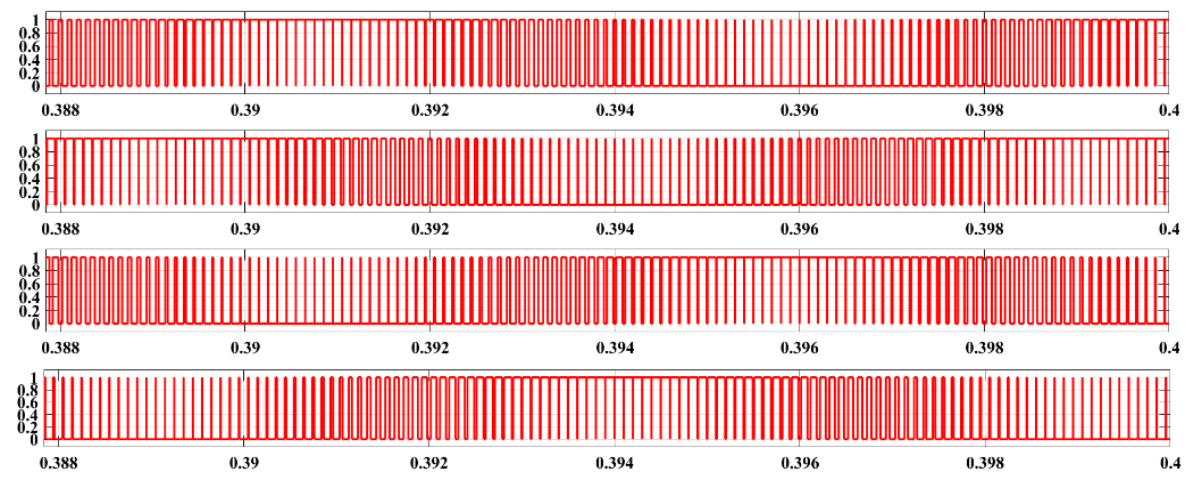

Figure 18. Gate pulses for FSTPI 
International Journal of Mathematical, Engineering and Management Sciences

Vol. 4, No. 6, 1325-1340, 2019

https://dx.doi.org/10.33889/IJMEMS.2019.4.6-104

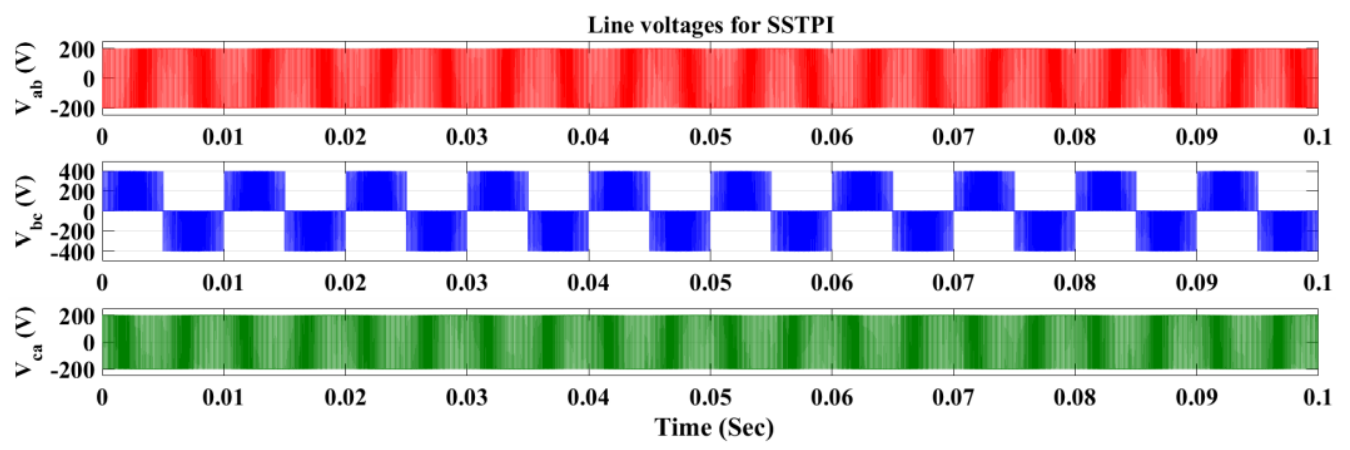

Figure 19. Output line voltages of FSTPI

\section{Conclusion}

In this paper an effort has been made to compare six and four switch three phase inverter based on space vector modulation for industrial applications. The comparison is made on the basis of overall cost incurred on the system i.e. economic aspects, types of losses and its impact on the efficiency and influence of the unbalanced DC link voltage on the performance of the inverter system. It is estimated that the overall cost of the FSTPI system will be reduced by $20 \%$ and the losses would reduce by $33 \%$ which is a significant advantage of the FSTPI system. Simulation results obtained shows that same modulation scheme may be used for achieving a comparable performance of four switch inverter w.r.t. six switch one, and balanced sinusoidal stator flux is maintained by selectively applying three of the four possible voltage space vectors for a given switching period $\mathrm{T}_{\mathrm{s}}$. After determining the suitable voltage vectors and their on-periods the pulses can be used to drive the FSTPI which may drive any load. This is a cheaper option as uses four switches instead of six resulting in a cost effective high performance inverter unit and by using robust controllers with suitable control techniques these inverters can be a suitable alternative for drives in industrial applications. In industrial drives application with four switch inverter is still under the process of research. Six switch inverters have many advantages such as symmetry of space vector over the four switch inverter. This paper provides a detailed comparison between FSTPI and SSTPI based on almost all the aspects that includes economic aspects, technical aspects including losses and efficiency which are required for the application of these inverters for industrial drives.

\section{Conflict of Interest}

The authors confirm that there is no conflict of interest to declare for this publication.

\section{Acknowledgement}

The authors would like to express their sincere thanks to the Management of Maulana Azad National Institute of Technology, Bhopal (M.P.) for providing the necessary support to carry out the work and to the editors and reviewers for their time and valuable suggestions for the improvement of the paper. 
International Journal of Mathematical, Engineering and Management Sciences

Vol. 4, No. 6, 1325-1340, 2019

https://dx.doi.org/10.33889/IJMEMS.2019.4.6-104

\section{References}

Badsi, B.E., Bouzidi, B., \& Masmoudi A. (2013). DTC scheme for a four-switch inverter-fed induction motor emulating the six-switch inverter operation. IEEE Transactions on Power Electronics, 28(7) 3528-3538.

Bose, B.K. (2004). Modern power electronics and ac drives. Pearson Education, Prentice Hall, ISBN-13: 9780130167439.

Bowes, S.R., \& Lai, Y-S. (1997). The relationship between space-vector modulation and regular-sampled PWM. IEEE Transactions on Industrial Electronics, 44(5), 670-679.

Correa, M.B.R., Jacobina, C.B., Da Silva, E.R.C., \& Lima, A.M.N. (2006). General PWM strategy for four-switch three-phase inverters. IEEE Transactions on Power Electronics, 21(6), 1618-1627.

Ghosh, S., Swarnkar, P., \& Deshpande, D.M. (2019). Control strategies governing induction motors as industrial drives- A technical review. International Journal on Emerging Technologies, 10(1), 97-105.

Hava, A.M., \& Emre, U. (2009). Performance analysis of reduced common-mode voltage PWM methods and comparison with standard PWM methods for three-phase voltage-source inverters. IEEE Transactions on Power Electronics, 24(1), 241-252.

Hava, A.M., Kerkman, R.J., \& Lipo, T.A. (1999). Simple analytical and graphical methods for carrierbased PWM-VSI drives. IEEE Transactions on Power Electronics, 14(1), 49-61.

Hee, H.H., Dzung, P.Q., Phuong, L.M., \& Bac, N.X. (2009). A new switching technique for direct torque control of induction motor using four-switch three-phase inverter with DC link voltage imbalance. IEEE International Conference on Industrial Technology, (pp. 1-6). Gippsland, VIC, Australia.

Jang, J-S., Park, B-G., Kim, T-S., Lee, D.M., \& Hyun, D-S. (2008). Sensorless control of four-switch threephase PMSM drive using extended Kalman filter. Proceedings of IEEE IECON, (pp. 1368-1372). Orlando, FL, USA.

Kabalyk, Y. (2016). Determination of energy loss in power voltage inverters for power supply of locomotive traction motors. Procedia Engineering, Elsevier, 165, 1437-1443.

Klima, J. (2006). Analytical investigation of an induction motor fed from four-switch VSI with a new space vector modulation strategy. IEEE Transactions on Energy Conversion, 21(4), 832-838.

Krause, P.C., Wasynczuk, O., \& Sudhoff, S.D. (2002). Analysis of electric machinery and drive systems. John Wiley \& Sons, Inc. ISBN: 0-471-14326-X

Kwasinski, A., Krein, P.T., \& Chapman, P.L. (2003). Time domain comparison of pulse-width modulation schemes. IEEE Power Electronics Letters, 1(3), 64-68.

Lee, D-C., \& Kim, Y-S. (2007). Control of single-phase-to-three-phase AC/DC/AC PWM converters for induction motor drives. IEEE Trans on Industrial Electronics, 54(2), 797-804.

Lee, D-C., \& Lee, G-M. (1998). A novel over modulation technique for space-vector PWM inverters. IEEE Transactions on Power Electronics, 13(6), 1144-1451.

Murai, Y., Gohshi, Y., Matsui, K., \& Hosono, I. (1992). High-frequency split zero-vector PWM with harmonic reduction for induction motor drive. IEEE Transactions on Industry Applications, 28(1), 105-112.

Narayanan, G., \& Ranganathan, V.T. (2002). Extension of operation of space vector PWM strategies with low switching frequencies using different over modulation algorithms. IEEE Transactions on Power Electronics, 17(5), 788-798. 
International Journal of Mathematical, Engineering and Management Sciences

Vol. 4, No. 6, 1325-1340, 2019

https://dx.doi.org/10.33889/IJMEMS.2019.4.6-104

Nguyen, T.D., Lee, H-H., \& Nguyen, H.M. (2010). Adaptive carrier-based PWM for a four-switch threephase inverter under DC-link voltage ripple conditions. Journal of Electrical Engineering \& Technology, 5(2), 290-298.

Salcone, M., \& Bond, J. (2009). Selecting film bus link capacitors for high performance inverter applications. IEEE International Electric Machines and Drives Conference, IEMDC, (pp. 1692-1699). Miami, FL, USA.

Thamizhazhagan, P., \& Sutha, S. (2017). Performance analysis of direct torque controlled PMSM drives using fuzzy logic. Journal of Electrical Engineering, 17(1), 259-264.

Vallabhai, M.J., Swarnkar, P., \& Deshpande, D.M. (2012). Comparative analysis of PI control and model reference adaptive control based vector control strategy for induction motor drive. International Journal of Engineering Research and Applications, 2(3), 2059-2070.

Wang, R., Zhao, J., \& Liu, Y. (2011). A comprehensive investigation of four-switch three-phase voltage source inverter based on double Fourier integral analysis. IEEE Transactions on Power Electronics, 26 (10), 2774-2787.

Wu, B. (2006). High power converters and AC drives. John Wiley \& Sons, Inc. ISBN-10: 0-471-73171-4.

Yousef, A.M., \& Abo-Elyousr, F.K. (2017). Fuzzy logic speed control for three-phase induction motor supplied by photovoltaic system with a robust MPPT. Journal of Electrical Engineering, 17(1), 148162.

Zaky, M.S., \& Metwaly, M.K. (2017). A performance investigation of a four-switch three-phase inverterfed IM drives at low speeds using fuzzy logic and PI controllers. IEEE Transactions on Power Electronics, 32(5), 3741-3753.

Zhou, D., Zhao, J., \& Liu, Y. (2015). Predictive torque control scheme for three-phase four-switch inverterfed induction motor drives with DC-link voltages offset suppression. IEEE Transactions on Power Electronics, 30(6), 3309-3018.

Zhou, K., \& Wang, D. (2002). Relationship between space-vector modulation and three-phase carrier-based pwm: a comprehensive analysis. IEEE Transactions on Industrial Electronics, 49(1), 186-196. 